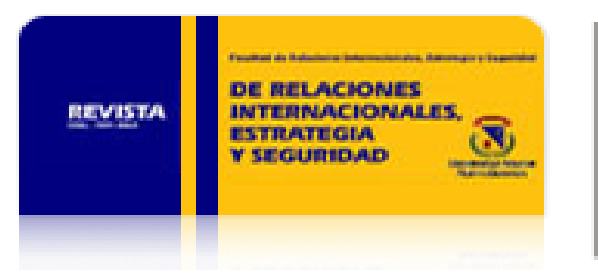

Revista de Relaciones Internacionales, Estrategia y Seguridad

ISSN: 1909-3063

cinuv.relinternal@unimilitar.edu.co

Universidad Militar Nueva Granada

Colombia

Cadena Montenegro, José Luis

Geografía política: tensión en las fronteras de Colombia como efecto de su conflicto interno Revista de Relaciones Internacionales, Estrategia y Seguridad, vol. 2, núm. 2, julio-diciembre, 2007

Universidad Militar Nueva Granada

Bogotá, Colombia

Disponible en: http://www.redalyc.org/articulo.oa?id=92720202

- Cómo citar el artículo

- Número completo

- Más información del artículo

- Página de la revista en redalyc.org

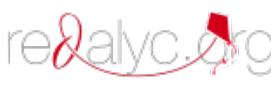

Sistema de Información Científica

Red de Revistas Científicas de América Latina, el Caribe, España y Portugal

Proyecto académico sin fines de lucro, desarrollado bajo la iniciativa de acceso abierto 
rev.relac.int.estrateg.segur.2(2):93-126,2007

\section{GEOGRAFÍA POLÍTICA: TENSIÓN EN LAS FRONTERAS DE COLOMBIA COMO EFECTO DE SU CONFUCTO INTERNO}

\section{RESUMEN}

Las fronteras de Colombia permanentemente han estado en situación de tensión desde su misma independencia y en tiempos modernos la situación no ha cambiado. En la primera década del siglo XX, Panamá se independizó y al poco tiempo, el país afrontó un crudo conflicto en defensa de su territorio cuando Perú lo invadió por su frontera sur en 1932. Con la República Bolivariana de Venezuela, especialmente, han sido muchas las situaciones conflictivas por razones de delimitación. Con Ecuador, Perú, Brasil y Panamá en los últimos años se han presentado diversos

\footnotetext{
${ }^{1}$ Geógrafo y Politólogo colombiano, Profesional en Ciencias Militares. Magíster en Ciencia Política, Universidad de los Andes; Magíster en Planeación Socioeconómica, Universidad Santo Tomás; Magíster en Geografía y Ordenamiento Territorial, convenio UPTC-IGAC. Doctor en Geografía, Universidad Nacional Autónoma de México, especialidad en Geopolítica. Presidente de la Asociación Colombiana de Geógrafos (ACOGE), Miembro de la Asociación de Historiadores de la Ciencia y la Humanidades, México, Miembro del Instituto de Política y Democracia, Brasil, Consultor internacional en Defensa y Seguridad. Ensayo escrito y revisado en septiembre de 2.007. Comentarios a: jlcadenam@yahoo.com.
} 
incidentes relacionados con el conflicto interno colombiano. Sin embargo, la diplomacia se ha encargado de evitar que los reclamos superen la racionalidad y desemboquen en acciones bélicas de incalculables consecuencias. Al iniciar el siglo XXI se ha dicho que las fronteras colombianas son porosas, inseguras y expuestas a las industrias ilícitas. De no adoptarse una posición seria y responsable en el tema de fronteras, Colombia podría tener un lamentable incidente.

Palabras clave: fronteras, integración, conflicto, geopolítica, abandono, diplomacia, tensión.

\begin{abstract}
Colombian borders have always been under tension or some kind of pressure. Since independence to modern times this situation has not changed much. At the onset of the twentieth century, Panama claimed its independence and later on in 1932 Colombia was in serious trouble protecting its territory from a Peruvian invasion through its southern border. The Colombian-Venezuelan border has been rather unstable and there remains a "border conflict" rather troublesome to settle. In recent years Ecuador, Peru, Brasil and Panama have become increasingly worried about the impact that the Colombian internal conflict may have in their border areas. Diplomacy is keeping those troubles within a relative prudent control, as far away as possible from actions that could bring about undesirable consequences. In the early twenty-first century Colombian borders are weak, insecure, and furthermore exposed to illegal activities. It must be realized that if serious, responsible and clear policies concerning border issues are not implemented, Colombia may well be at the edge of serious international conflict.
\end{abstract}

Key words: borders, integration, conflict, geopolitics, diplomacy, tension, Colombia

\title{
INTRODUCCIÓN
}

El concepto de franja fronteriza es de origen aduanero y corresponde a una extensión territorial comprendida entre una línea real y otra imaginaria, trazada paralelamente a una distancia de 20 kilómetros. El área así definida goza de las reglamentaciones especiales vigentes, referidas sobre todo a franquicias aduaneras. Sin embargo, los problemas fronterizos modernos están relacionados con otras causas y producen efectos más graves que los derivados del incumplimiento de las leyes aduaneras. 
El episodio más destacado en la historia de Colombia y sus relaciones fronterizas, indudablemente es la pérdida de Panamá. Al comenzar el siglo XX Colombia perdió un importante territorio que les permitió a los Estados Unidos de América alcanzar sus metas económicas y el control militar de la región para mantenerse como la primera potencia mundial. El Canal de Panamá se construyó después de la abrupta separación mediante un movimiento independentista apoyado desde Norteamérica. Si se consideran los planes regionales e iniciativas económicas y comerciales que los Estados Unidos han puesto en marcha en Latinoamérica durante el siglo XX y comienzos del XXI, será fácil entender los nuevos enfoques de la geopolítica, cuya práctica ya no está orientada a la usurpación de territorios sino a la conquista de mercados y a la obtención de recursos que aseguren la supervivencia.

En los límites de Panamá y Colombia se encuentra el Tapón del Darién, selvático territorio de gran importancia por la biodiversidad que alberga y por donde está trazada la carretera panamericana que unirá a Canadá con Chile. (GARCÍA: 1945). Se trata de la misma selva que produjo cientos de muertes durante la construcción de la gigantesca obra. Aunque la vía fue trazada hace muchos años, por falta de recursos y por protestas de las comunidades que defienden el medio ambiente, el tramo no se ha construido.

La separación de Panamá sucedió el 3 de noviembre de 1903. Ese día, la Junta de Notables declaró su Independencia y acto seguido, los Estados Unidos de América reconocieron al nuevo Estado. Panamá recibió como premio diez millones de dólares, los cuales fueron administrados por el Banco Morgan por un grupo de especuladores norteamericanos que habían apoyado los sucesos de la separación. El dinero que salió del tesoro nacional, regresó a los bancos norteamericanos en un círculo vicioso que hasta nuestro tiempo se practica y deja dividendos al sistema financiero internacional.

Panamá fue una provincia de Colombia hasta principios del siglo XX y su independencia fue apoyada con la clara intención de construir del canal inter-oceánico. Su frontera física con Colombia es de 225 kilómetros de extensión y sus rasgos culturales son comunes, lo que confirma que en realidad, la vocación de Panamá es caribeña y andina, tanto geográfica como históricamente (CADENA: 2005). Una larga sucesión de hechos geopolíticos auspiciados por los Estados Unidos, terminaron en una revuelta difícil de sofocar por el gobierno que atendía otros conflictos internos y que militarmente no estaba en capacidad de aplicar la fuerza para hacer cumplir la ley. Así fue la separación de Panamá y a continuación se construyó el Canal Interoceánico que pasó a ser el símbolo del poder económico y militar, pues con el pretexto de su propia seguridad, en la zona aledaña al mismo se construyó por los Estados Unidos, una inmensa fortaleza. 
La instalación de enclaves militares estadounidenses en zonas estratégicas de América Latina tuvo sus orígenes en la apropiación del Canal de Panamá, donde se estableció el centro de operaciones estadounidenses para toda la región denominado Comando Sur (USSOUTHCOM, por sus siglas en inglés) y que desde hace poco tiempo fue trasladado a Miami; Pero desde Panamá, sus ramificaciones se extendieron a todos los puntos claves del continente. Colombia y los países limítrofes son ahora el epicentro de los asentamientos estadounidenses; sin embargo, el dispositivo estratégico y militar se extiende hasta los confines patagónicos de América Latina. (SALAZAR: 2002)

En 1968, mediante un golpe de estado, Ilegó al poder en Panamá el General Omar Torrijos, representante de un nuevo nacionalismo que se propuso recuperar la Zona y el Canal para su país. Torrijos acudió a la diplomacia para lograr sus objetivos, incluyendo una sesión del Consejo de Seguridad en Panamá. A la persistente estrategia de Torrijos para la recuperación de esos activos estratégicos se unieron como circunstancia afortunada, la visión democrática en cuanto a las relaciones internacionales del presidente norteamericano, Jimmy Carter, y el concurso de un decidido grupo de gobernantes latinoamericanos con cuyos consejos, apoyo y actitud solidaria, el Continente contribuyó a la resolución afortunada del problema a favor de Panamá.

El General Torrijos con un fuerte apoyo popular adelantó una política reformista con la que consiguió respaldo interno y externo. Desarrolló en Panamá profundas reformas sociales y en el ámbito externo se apoyó en el entonces poderoso Movimiento de Países No Alineados, obteniendo para su causa el apoyo latinoamericano en pleno. En 1976, Jimmy Carter venció en las elecciones a Gerald Ford y fue elegido presidente de los Estados Unidos, emprendiendo una política internacional de apoyo a los derechos humanos y a las democracias, que contrastó con la del frío realismo de Henry Kissinger en el Departamento de Estado. Retiró el apoyo norteamericano a las dictaduras de Pinochet en Chile y Somoza en Nicaragua, suspendió la ayuda militar a El Salvador, donde apoyó nuevas formas para la solución del conflicto interno, reconoció a la República Popular China, propició los acuerdos de Camp David entre Egipto e Israel, y logró con Panamá los Tratados de 1978. La posición de Jimmy Carter frente a estos temas y el fallido rescate de unos rehenes norteamericanos en Irán, incidieron negativamente para su reelección. La derecha de los Estados Unidos, encabezada por Ronald Reagan, manipuló en su beneficio electoral la negociación sobre los rehenes y sobre la devolución del Canal dijo: "Nosotros lo compramos, pagamos por él, es nuestro y lo vamos a guardar" (TIRADO: 2004).

El 24 de marzo de 1975 se suscribió la llamada Acta de Contadora, con el apoyo de los presidentes Alfonso López Michelsen de Colombia, Daniel Oduber de Costa Rica y Carlos Andrés Pérez de Venezuela quienes conjuntamente con el General Omar Torrijos, habían 
constituido el Primer Grupo de Contadora, para facilitar la negociación. Se trataba de gobiernos aparentemente progresistas de países vecinos y solidarios con la causa de Panamá. Pero en el caso colombiano, a los elementos anteriores se agregaba la circunstancia de que Colombia tenía derechos consagrados por el Tratado Urrutia-Thomson, los cuales quería conservar. (TRATADO U-T: 1914)

Desde el sector norteamericano opuesto a la negociación se insinuaba que si ella no avanzaba, era debido a las pretensiones de Colombia respecto a sus derechos. En Panamá, existían sectores que consideraban que el tratado entre Colombia y los Estados Unidos era entre terceros para ellos y, en consecuencia, ninguna obligación vinculaba a Panamá. El asunto para Colombia era, cómo mantener sus derechos, cómo apoyar la justa demanda panameña y, al mismo tiempo, no ser, ni aparecer, como el impedimento para que la negociación avanzara. Muchas de las gestiones del Grupo se realizaron en Bogotá y en ocasiones el General Torrijos obtuvo asesoría y apoyo cercano del presidente Alfonso López Michelsen.

En lo que respecta a Colombia, en el texto del Acta de Contadora se destaca lo siguiente: en el Preámbulo se hace explícito el apoyo a los derechos inalienables de Panamá y se expresa que el Canal está sujeto a los riesgos derivados de una acción nuclear en caso darse un conflicto internacional. Por estar sujetos a esos riesgos debido a la vecindad, Panamá declara que al ser aprobado el nuevo tratado con los Estados Unidos, está dispuesta a celebrar un nuevo acuerdo con Colombia y Costa Rica para otorgarles beneficios de tránsito por el Canal a sus correos, bienes y mercancías y para permitirles en todo tiempo el tráfico de tropas, naves y materiales de guerra (Acta de Contadora: 1986).

En el Acta se lee que una vez Panamá y los Estados Unidos suscribieran un nuevo tratado, Colombia "renuncia a todo derecho otorgado por el tratado con respecto a materias que son propias de exclusiva jurisdicción soberana de la República de Panamá". Lo del Preámbulo, relacionado con los daños derivados del peligro nuclear, permitía allanar el camino para que Colombia pudiera renunciar a los derechos derivados del tratado Urrutia-Thomson, recibiéndolos a su vez de Panamá, y demostrando así que no se convertía en un obstáculo para la negociación. Al establecer el tránsito de tropas y elementos militares "en todo tiempo", superaba la limitación impuesta por el Tratado de 1921, que reducía ese tránsito a tiempos de paz, cuando, si en algún momento se necesita más, es en tiempos de conflicto.

Los derechos de Colombia otorgados por Panamá se formalizaron en el Tratado Uribe VargasOzores, o también Ilamado de Montería, suscrito en esa ciudad colombiana el 23 de agosto de 1979, durante el gobierno del presidente Julio Cesar Turbay Ayala, incluyendo los derechos de tránsito por el ferrocarril, "siempre que esté interrumpido el tráfico por el canal", los que no se habían mencionado expresamente en el Acta de Contadora. Lo único cierto después de 
tantos tratados, es que Colombia fue despojada de un territorio estratégico que le hubiera permitido alcanzar una mejor ubicación en el concierto internacional y unos recursos económicos que hubieran facilitado su desarrollo (TIRADO: 2004).

A finales del siglo XX y comienzos del XXI, en América del Sur se instalaron otras bases militares por parte de los Estados Unidos; así, en el marco del Plan Colombia, se reforzaron las base de Tres Esquinas, Larandia, Puerto Leguízamo en el sur y Melgar en el centro del país. Estos cuatro sitios de interés en la lucha contra el narcotráfico se convirtieron en receptores permanentes de armamentos, logística y contratistas asesores estadounidenses autorizados por el Congreso de ese país. En Perú, se establecieron las bases de lquitos y Nanay, ésta última en la zona amazónica, las dos con intervención del personal militar de Estados Unidos.

En los límites amazónicos de Colombia, los Estados Unidos consiguieron instrumentar un complejo militar-económico muy importante, que está basado en el Plan Iniciativa Regional Andina. De esta manera en Ecuador, se instaló la base de Manta, en un área considerada estratégica. Esta base por obvias razones, está ligada al Plan Colombia y a las actuales estrategias de Estados Unidos en dos aspectos:

1- Al Plan Colombia, como componente militar logístico de inteligencia en tiempo real, para apoyar operaciones tácticas contando con los nuevos mecanismos operativos que el siglo XXI ha traído para uso del complejo militar de los Estados Unidos.

2- $\quad$ A la agenda de seguridad de Estados Unidos como enclave geopolítico y observador adelantado en el sur del continente. Ya antes del 11 de septiembre de 2001, especialistas militares ecuatorianos como el General René Vargas Pazzos, actualmente (2007) embajador en Venezuela y el Coronel Jorge Brito, habían advertido el rol de la base de Manta: “En el acuerdo suscrito con Estados Unidos incluyen una flota de aviones de última generación, tan grande que puede transportar una unidad completa de infantería armada y equipada. ¿Para qué quieren en Manta un avión militar tan grande? ¿Para detectar traficantes de drogas? Esos aviones sirven para montar una operación militar de ataque a gran escala desde Manta". (BRITO: 2003)

Adolfo Pérez Esquivel, premio Nóbel de paz, refiriéndose al Plan Colombia, aseguró que "esta situación responde a políticas y a visiones geopolíticas continentales de Norteamérica, que apuntan a la colonización de Latinoamérica. Creo, en consecuencia que estamos frente a una situación difícil, no imposible de revertir, a través de la unidad del continente, de propuestas políticas alternativas para poder avanzar en proyectos propios" (PÉREZ: 2003). 
A finales de noviembre del año 2003, se llevó a cabo en Brasil el Foro del Acuífero Guaraní, que se convirtió en una forma de rechazar la avanzada extranjera sobre ese sector, ya que el Banco Mundial viene impulsando con más fuerza su conservación y protección mientras se concreta la idea de considerar el agua un bien comercial y no un bien social. Ni más ni menos se está hablando de privatizar el agua en sus nacimientos y convertirla en un producto de marca con precios internacionales y exclusividades en su explotación. Con razón desde hace algún tiempo se viene asegurando que "las próximas guerras serán por el agua". A esto bien le podríamos denominar "la geopolítica del agua", la cual está inmersa en los diferentes planes impulsados por los Estados Unidos.

Mientras los gobiernos latinoamericanos creyeron que el Plan Colombia era sólo para Colombia, éste paulatinamente se acerca a la Iniciativa Regional Andina, ahora acompañada de la Estrategia Continental de Seguridad Antiterrorista, uno de cuyos objetivos es homogeneizar la región para la próxima década en torno a la Iniciativa de Defensa Estratégica. Además, el Área de Libre Comercio de las Américas, que de México a Centroamérica se extiende con el Plan Puebla Panamá, converge en los Andes como macro-objetivo del Plan Colombia y la Iniciativa Regional Andina, cuyo epicentro es toda la región, que abarca siete territorios estratégicos cuyas capitales son Caracas, Bogotá, Quito, Lima, La Paz, Panamá y Brasilia. Este plan pretende convertirse en cabeza de playa para la conquista de un mercado de 800 millones de latinoamericanos (FERNÁNDEZ: 2001). Esto confirma la tesis que la geopolítica ya no se interesa en la expansión territorial, sino en el crecimiento del capital a través de las empresas transnacionales.

\section{PLANES REGIONALES EN LATINOAMÉRICA Y CAMBIOS EN EL DISPOSITIVO MILITAR}

La agenda de seguridad de los Estados Unidos, el narcotráfico y el terrorismo internacional, han generado nuevos planes en y para América Latina, que pasan estratégicamente por Colombia y que alteran las relaciones inter fronterizas entre los países considerados en esos planes.

El Plan Colombia: fue publicitado por Washington y Bogotá a finales de la década de 1990 como "un Plan Integral para el Fortalecimiento del Estado, la Democracia, los Derechos Humanos y la Paz de Colombia", pero luego su verdadera metamorfosis lo llevó a mostrarse como la solución militar del complejo conflicto socio-político-militar de éste país. Y es que éste plan da prioridad y asigna mayores recursos a su componente militar, cuyas aristas llegan al puerto ecuatoriano de Manta a través de tres componentes: 1- La transferencia de tecnología de punta, 2- La inteligencia electrónica y el rastreo satelital, que posibilitarían el éxito del nuevo instrumento con miras a garantizar la hegemonía de Estados Unidos en Suramérica, 3- La reconversión política 
y militar latinoamericana hacia la "lucha antidrogas" y a las concepciones estratégicas del antiterrorismo para neutralizar las llamadas "nuevas amenazas internas" (SALAZAR: 2002).

El Plan Puebla Panamá: Lanzado desde México en 2001 como la solución a problemas endémicos de ocho estados mexicanos y siete países centroamericanos, mediante la implementación de grandes iniciativas económicas, el plan después de seis años nada en concreto puede mostrar. A Colombia se le prometió que podría incorporarse como miembro asociado al PPP hasta después de junio del 2005, cuando se cumplieran cuatro años del mecanismo regional, y mientras tanto participaría como observador. En calidad de tal, Colombia podrá proponer temas y discutirlos con los ocho países fundadores del PPP, sin embargo, hasta que sea aceptado como miembro asociado podrá tener derecho a voz y voto, explicó Taylor, coordinador del PPP durante un seminario sobre el plan. Estas fueron algunas de sus declaraciones:

El Plan Puebla Panamá tiene la limitación de que no va a tener asociados sino hasta después del 15 de junio del 2005, cuando cumple cuatro años. Entonces, el tiempo más cercano para Colombia sería en ese cuarto aniversario para que él o cualquier otro país pueda tener calidad de asociado, añadió. EI PPP estipula tres figuras para los países miembros: observador, asociado y fundador. Esta última figura sólo la pueden tener las naciones que iniciaron el mecanismo: México, Belize, Nicaragua, Panamá, Honduras, Costa Rica, Guatemala y El Salvador (BID: 2002)

Efectivamente, en el 2007, Colombia pasó a ser miembro asociado del Plan Puebla Panamá pero la primera referencia pública de la intención de Colombia para ingresar al mismo fue hecha por el presidente Álvaro Uribe Vélez en el marco de una visita a México el 30 de mayo de 2004, sin embargo la Cancillería colombiana ya había notificado a los miembros del plan, su interés en participar. La comisión ejecutiva del PPP había sugerido a las cancillerías de los países miembros incorporar a Colombia como observador, las cuales tendrán la decisión final.

Es paradójico que se acepte el ingreso de este nuevo socio al PPP cuando precisamente uno de los argumentos del mismo consiste en negar a Colombia y Venezuela las posibilidades de incidir económicamente en la región de acuerdo con la misión y visión del plan. El presidente Álvaro Uribe Vélez había anunciado que de ser aprobado su ingreso al PPP, Colombia iniciaría obras de infraestructura para unir a Centroamérica con Suramérica. El tramo del Darién en límites con Panamá es la única parte de carretera que falta construir para completar la vía Panamericana; estos trabajos no se han podido ejecutar por diferentes problemas entre los que se pueden mencionar, falta de recursos, el conflicto armado interno en Colombia, pues la zona es teatro de operaciones entre bandas de narcotraficantes, de las FARC y las Autodefensas Unidas de Colombia, además del desinterés de los inversionistas por las razones anteriores, entre otras. 
El primer proyecto será la construcción de una carretera que una Colombia con Panamá, por un sitio diferente al tapón del Darién y una línea de interconexión eléctrica. También se buscará un acuerdo con Venezuela para construir desde ese país y hasta Panamá un gasoducto, el cual se firmó efectivamente después de una visita que el mandatario colombiano hiciera a principios de julio de 2004 a Venezuela y en la que el presidente Hugo Rafael Chávez Frías estuvo de acuerdo, posiblemente, por su intención de exportar hidrocarburos hacia el lejano oriente por el Océano Pacífico. Taylor afirmó que el Plan Puebla Panamá "está vivo" y avanza, aunque reconoció que ha faltado una estrategia para dar a conocer entre la gente los beneficios y lo que se ha hecho. Aseguro también que en México se iniciará una campaña de difusión en radio y televisión para informar sobre el PPP. Muchos críticos, entre los que se cuenta quien esto escribe, aseguran que el PPP nació muerto por falta de recursos económicos y de capital político (CADENA: 2005).

Iniciativa Regional Andina: Hipotéticamente es una extensión del Plan Colombia, que incluye aspectos militares y comerciales dirigidos a siete países de América del Sur. Fue activado en el año 2001 con el financiamiento de Estados Unidos y abarca Colombia, Ecuador, Venezuela, Bolivia y Perú (denominados países Bolivarianos en honor al Libertador Simón Bolívar), Brasil y Panamá. Es conveniente aclarar que Venezuela se negó desde el año 1999 a que su espacio aéreo fuera utilizado por aviones plataforma para tareas de guerra electrónica e interdicción con el pretexto de luchar contra las bandas de narcotraficantes. De igual forma, el gobierno de la República Bolivariana de Venezuela exigió a los Estados Unidos el retiro de su misión militar acantonada en el Fuerte Tiuna, un complejo militar ubicado en Caracas, en el cual habían permanecido por varias décadas. Por este motivo las relaciones entre Estados Unidos y la República Bolivariana de Venezuela se encuentran deterioradas en el aspecto político, más no en el comercial. El Departamento de Estado de los Estados Unidos de América, en su página web define así la Iniciativa Regional Andina:

\footnotetext{
"La región Andina representa un reto significante y una oportunidad para la política exterior de los Estados Unidos en los próximos años. Dentro de la región se están enfrentando intereses nacionales importantes para los Estados Unidos. La democracia esta bajo presión en todos los países de los Andes. El desarrollo económico es lento y el progreso hacia la liberalización es inconsistente. Los Andes continúan produciendo virtualmente toda la cocaína del mundo y han incrementado las cantidades de heroína, por lo tanto representan un reto directo a nuestra salud pública y seguridad nacional. Todos estos problemas están interrelacionados. Los problemas de la región necesitan ser considerados comprensivamente para el avance de los intereses de los Estados Unidos en sus relaciones exteriores dentro de la región.
}

La Administración esta proponiendo una iniciativa para proveer asistencia a los países Andinos. El presupuesto requerido por la Administración para el año fiscal 2002 es de \$882 millones de dólares 
para el financiamiento de asuntos internacionales para programas contra el narcotráfico, construcción de instituciones democráticas, y asistencia para el desarrollo en los siete países incluidos en la iniciativa: Bolivia, Brasil, Colombia, Ecuador, Panamá, Perú, y Venezuela. En contraste al último año de suministros al Plan Colombia, menos de la mitad de la asistencia será para Colombia y solamente el 50 por ciento será para el fortalecimiento de la ley y asistencia en seguridad. Hemos informado esta iniciativa en términos generales a los otros países donantes y a las naciones receptoras, y ha sido bien recibida. Hemos empezado consultas con el Congreso en lo concerniente con nuestra presentación del presupuesto de la Administración. Quizás la contribución más grande a corto plazo para el crecimiento económico y la prosperidad en los Andes seria la renovación del Tratado de Comercio de Preferencia Andina (ATPA) y expansión de sus beneficios. Nosotros creemos que la renovación del ATPA es una parte integral de la Iniciativa Andina. La legislación fue originalmente promulgada para proveer alternativas económicas al narcotráfico en Bolivia, Perú, Ecuador, y Colombia, y ha sido exitosa hasta ahora". (Departamento de Estado: 2001 original en inglés).

\section{LAS CINCO FRONTERAS POROSAS DE COLOMBIA}

Además de los continuos conflictos fronterizos, el secuestro de 12 ciudadanos extranjeros en el año de 1999 en Tarapoa, población ecuatoriana limítrofe con Colombia, disparó las alarmas en ese país y en los vecinos y dejó claro que la militarización intensiva no es la solución a los viejos problemas relacionados con inseguridad fronteriza. En años anteriores, el gobierno de Ecuador había ordenado a sus jefes militares en repetidas oportunidades el despliegue inmediato de tropas en sectores limítrofes con Colombia para repeler ataques y secuestros por parte de grupos de la guerrilla colombiana en zona de frontera. En el caso de los 12 secuestrados, fueron las FARC las responsables del ilícito y la reacción de los vecinos de Colombia no se hizo esperar. Brasil y Perú enviaron más de 5.000 soldados a la frontera con su vecino común. A raíz de ese acontecimiento, efectivos de la Guardia Nacional panameña ocuparon las selvas del Darién, incluso la presidenta de ese país, Mireya Moscoso, visito la línea fronteriza y la recorrió con algunos de sus colaboradores.

\section{Problemas en la Frontera Colombo-Venezolana}

Esta franja fronteriza se define por la extensión territorial de 2.219 kilómetros que sirve de límite entre 7 departamentos (Guajira, Norte de Santander, Santander, Boyacá, Arauca, Vaupés y Guainía) y cuarenta y tres municipios en Colombia y cuatro estados (Zulia, Táchira, Apure y Amazonas) y veinte municipios en Venezuela. Definitivamente es la frontera más conflictiva en la región. 
Cuando del análisis de conflictos fronterizos se trata, es importante considerar en primer lugar los aspectos culturales, antropológicos, etnográficos, sociológicos y los procesos históricos y políticos que han dado lugar a la conformación del Estado. En el pasado, en América del Sur, la regla general era que el poder estatal no alcanzaba a llegar a las zonas fronterizas de los territorios nacionales y las fronteras fueron fijadas por el famoso Uti Possidetis de 1810 que dio origen a conflictos y desacuerdos político-fronterizos en los dos siglos anteriores, inclusive llegó a modificar el mapa político del continente, aunque no alcanzó a afectar la vida de los pueblos en forma vital y permanente.

No se entendía y parece que aún hoy no se entiende que la frontera es el producto del movimiento del poder estatal, en contraste con un límite natural que es a la vez una zona de contacto de una región natural con otra. El Estado-Nación se caracterizó y simbolizó simultáneamente por un territorio, una historia, una sociedad, una moneda, una cultura, etc. Sin embargo, como producto de la globalización, la formulación e instrumentación de proyectos nacionales están siendo condicionados por nuevas determinaciones externas. Esta situación provoca que la soberanía de las naciones esté cada vez más acotada y condicionada, sobre todo en aquellos países cuyos gobiernos manifiestan una situación de debilidad para defender ciertos intereses nacionales frente a agentes, instituciones y organizaciones de carácter internacional. (GASCA: 2002).

La frontera colombo-venezolana ha sido objeto de estudio de numerosos tratadistas e historiadores por la serie de problemas que en ella se han generado y que han repercutido en las relaciones bilaterales de los dos países; para abordar esta situación, los diferentes gobiernos han designado misiones diplomáticas destinadas a desarrollar la compleja situación que se presenta a lo largo de la línea fronteriza, agravada por delitos conexos con la emigración ilegal que se suele practicar por parte de ciudadanos de los dos países. Se puede decir que a lo largo de esa frontera existe un ambiente de seguridad vulnerable que ha impedido el desarrollo y la integración. A raíz de estos problemas, los dos países hermanos han contemplado en sus planes estratégicos, hipótesis de guerra con alternativas de ataque y defensa.

La permanente tensión fronteriza se refleja en la densa hemerografía que se alimenta diariamente con las informaciones en el ámbito de las declaraciones de autoridades que tienen que ver con lo que allí sucede y por eso no resulta difícil obtener abundante información con detalles y planteamientos del problema despertando gran interés entre quienes desean conocer esta circunstancia geopolítica de dos países con una historia enraizada en el mismo proceso de la independencia, pregoneros del pensamiento bolivariano, practicantes de una sola cultura, víctimas de una violenta colonización y hermanos en la pobreza incrementada por luchas políticas y gobernantes inescrupulosos de corte caudillista que con intenciones chauvinistas despertaron falsos sentimientos de patriotismo en décadas anteriores. Pese a 
tantas cosas en común, no ha sido posible un desarrollo rural y fronterizo sustentable para una convivencia pacífica y por el contrario, estas zonas generalmente son las más deprimidas por inasistencia estatal.

Teóricamente el desarrollo rural fronterizo se fundamenta en tres ejes a saber: 1- Satisfacción de las necesidades básicas de la población y cubrimiento de las necesidades insatisfechas de los pobres del mundo 2- Potenciamiento de la capacidad de la esfera de vida para absorber los efectos de las actividades humanas, así como previsión del impacto sobre los recursos del ambiente 3- Consideración que los límites del desarrollo están dados por el estado actual de la organización tecnológica y social (FAO/CONAZA/SEDESOL: 1994). Ninguna de estas condiciones se ha dado en esta extensa y problemática frontera y por el contrario, allí reina la violencia, la pobreza, la ignorancia y los daños ambientales.

Se mencionan en este artículo algunas de las variables más críticas en esa relación que ha tenido sus vaivenes y momentos álgidos, y que aún subsisten a pesar de las aparentes buenas intenciones que subyacen en la sociedad civil de esas regiones, más que en las autoridades de los dos Estados. Es un tema complicado en el que intervienen numerosos factores que en razón del espacio editorial no es posible tratar en extenso y en tal virtud se plantearán los problemas más frecuentes y algunas características de esta singular relación de dos países hermanos inmersos en un diferendo generado por lo que se ha llamado una frontera conflictiva que requiere no solamente de un diagnóstico cuidadoso, sino de soluciones que satisfagan las pretensiones de los involucrados en la situación y den inicio a un proceso de entendimiento profundo y provechoso, teniendo como base la diplomacia, el diálogo, el sentido común y el derecho internacional.

\section{Características de la Región Fronteriza}

La región fronteriza colombo-venezolana se ha caracterizado por la ausencia significativa del Estado, notoria a simple vista por deficientes y en algunos casos inexistentes servicios de salud, educación, recreación, infraestructura, entre otros, fuerte militarización y la reiterada y sistemática violación de los derechos humanos a la población que habita en esta región. En los últimos años, la tensión se ha incrementado por el fenómeno del narcotráfico que dejó de ser un problema exclusivo de Colombia para afectar a toda la región latinoamericana. En las montañas limítrofes se siembra coca y amapola y se realiza el proceso completo desde la siembra hasta la exportación, con participación de ciudadanos de los dos países, amparados por la violencia de los grupos armados delincuenciales a los que me referiré con algún detalle.

La seguridad fronteriza teóricamente ha sido una cuestión de Estado para Venezuela y Co-

lombia que ha despertado mayor interés en Venezuela, por las consecuencias negativas que 
las acciones de grupos guerrilleros, paramilitares y de la delincuencia común han generado, al desplazarse desde territorio colombiano hasta territorio venezolano y viceversa, todo ello ha ocurrido en el transcurso de la dos últimas décadas. A tal punto llegó la tensión que algunas autoridades venezolanas encargadas del control e ingreso de extranjeros, identificaban la nacionalidad colombiana como sinónimo de guerrilla, tráfico de drogas o secuestro y veían a los nacionales colombianos como enemigos y les endilgaban la responsabilidad de sus desdichas, en una evidente expresión de xenofobia. Las incursiones de guerrilla y paramilitares colombianos han servido de justificación para que distintas autoridades detengan y maltraten en oportunidades a los habitantes de esta zona, acusándolos de pertenecer a esos grupos o de colaborar con ellos. Las comunidades indígenas han sido las víctimas más frecuentes de la acción policial o militar de las autoridades venezolanas.

\section{Antecedentes Históricos}

Nada parece provocar más controversia entre los científicos sociales, y particularmente entre los geógrafos, que la definición de región fronteriza. El dilema consiste en conciliar la heterogeneidad de un área tan vasta con el denominador común que representa la vecindad con otras culturas.

Los problemas fronterizos entre Venezuela y Colombia se iniciaron inmediatamente después de haberse consumado la desintegración de la Gran Colombia, cuyo proceso histórico va desde el año 1833 hasta el año 1941 lapso en el que se firmaron tratados de amistad, alianza comercial, límites y navegación entre los presidentes de Venezuela y Colombia. A raíz de la firma de los mismos comenzaron a surgir descontentos en la zona fronteriza por parte de los dos países, provenientes de la demarcación de fronteras, debido a que en estos convenios según algunos venezolanos, su país estaba perdiendo la soberanía que tenía en importantes áreas en la península de la Guajira, en el Zulia y en el Táchira. Todas estas discrepancias fueron dirimidas mediante el Tratado de Límites entre Venezuela y Colombia, firmado el 05 de abril de 1941. No obstante la firma de ese Tratado, en las últimas décadas han surgido nuevos problemas, los cuales pueden clasificarse fundamentalmente en tres aspectos: geográficos, socioeconómicos, político-culturales.

Los problemas de orden geográfico: algunos teóricos venezolanos argumentan que se deben a la artificialidad de la frontera, pues según ellos, no está determinada en muchos tramos por accidentes geográficos, sino por líneas establecidas mediante cálculos de latitud y longitud; a esto se le suma la inestabilidad de la línea de demarcación, como es el caso de algunos ríos que alteran su curso constantemente. Desconocen quienes así piensan que las fronteras son básicamente de dos tipos: naturales y artificiales y que dependiendo de los arreglos debidamente firmados por representantes de los gobiernos, tienen validez ante la comunidad internacional (LÓPEZ: 1999). 
La extensa frontera terrestre colombo-venezolana, constituye un eje amplio y de geografía heterogénea, por ejemplo, la zona norte o de la Guajira, es plana y básicamente desértica, no obstante en otras zonas pueden encontrarse selvas y montañas muy pronunciadas, como las del Catatumbo, así como grandes ríos entre los cuales están el Arauca y el Orinoco en pleno límite. Gran parte de los caudales hídricos que surten a Venezuela tienen origen en las cuencas colombianas, pues este país tiene páramos como pocos en el mundo, los cuales comúnmente son llamados fábricas de agua, por asuntos relacionados con el fenómeno de la evapotranspiración.

Los problemas de orden socioeconómico: el principal ha sido el contrabando, que en décadas anteriores se debió principalmente a la diferencia del poder adquisitivo de las monedas de los dos países. La moneda venezolana, el bolívar, tenía mayor valor que el peso colombiano, en consecuencia el contrabando se realizaba desde Colombia hacia Venezuela, a través de la Depresión del Zulia y del Río Orinoco. Esta actividad beneficiaba el comercio informal de algunas ciudades colombianas como Maicao, Cúcuta, Arauca y Puerto Carreño. Hoy en día (2007) la situación funciona a la inversa porque el bolívar se encuentra a tasas de cambio inferiores que el peso colombiano. La gasolina venezolana es de bajo costo y por lo tanto el contrabando de ese combustible ha sido permanente hacia Colombia, transformándose en una fuente de empleo informal para miles de colombianos y venezolanos que por física necesidad, acogieron esa actividad como una forma de vida.

Los niveles y expectativas económicas son desiguales a lo largo de la frontera colombo-venezolana. Mientras por un lado existen zonas que carecen de los más elementales servicios, como la Guajira venezolana y el Arauca colombiano, en cambio otras localidades desarrollan tareas de gran proyección económica, como la actividad petrolera en los municipios Venezolanos de Jesús Enrique Losada, Rosario de Perijá, Catatumbo y la actividad comercial y turística en el eje Cúcuta-San Antonio-San Cristóbal. Esta desigualdad económica genera problemas sociales relacionados estrechamente con la calidad de vida de los habitantes de la región pues las regalías en uno y otro país se han manejado localmente sin que haya solidaridad de carácter regional, nacional y menos internacional. Únicamente hasta comienzos de la década del 2000 el estado venezolano logró incidir en las administraciones locales para que, con carácter solidario inviertan en proyectos de gran impacto social en la región.

Desde hace varios años, Venezuela ha construido carreteras de primera categoría en los límites fronterizos, entre tanto Colombia carece de vías suficientes que puedan generar desarrollo y bienestar en su territorio. La diferencia es marcada a favor de Venezuela en ese aspecto como complemento a su dispositivo militar fronterizo. Ese país ha implantado los Teatros de Operaciones, que actúan con base en grandes guarniciones compuestas fundamentalmente por fuerzas terrestres, aéreas y fluviales o navales. 
Gran importancia ha dado Venezuela a la protección de sus Parques Naturales en la frontera mientras Colombia apenas hace presencia en los suyos. La situación es de tal magnitud, que para llegar al Parque Nacional Natural El Tuparro, es más conveniente entrar por Venezuela. Los incendios en este parque han alcanzado hasta 40.000 hectáreas en tiempo de sequía sin que el Estado colombiano haya sido capaz de sofocarlos; allí las guerrillas de las FARC han establecido uno de sus santuarios desde hace décadas. Recordando al geógrafo colombiano Ernesto Guhl, bien vale la pena decir que "un Estado no es imaginable sin una base espacio territorial y son el poder político y militar estatales los que determinan el dominio territorial del mismo, fijando sus fronteras como una realidad política" (GUHL: 1991). Pues bien, en esta zona no ha existido dominio territorial, haciéndose realidad aqueIla máxima que dice que "un espacio no controlado por el Estado al que pertenece, es ocupado por otro" (CADENA: 2002).

Para los venezolanos, la infraestructura vial en el occidente permite un desplazamiento ágil de sus tropas de superficie. Además, las bases navales y aéreas garantizan la movilidad en la región. Igualmente, Venezuela monitorea la frontera con radares y tecnología de punta. Pese a esto, la porosidad de esa extensa frontera permite la generación de problemas relacionados con el viejo concepto de la soberanía nacional. Así las cosas, la tranquilidad de la región y la integración latinoamericana están ligadas a la solución del conflicto interno colombiano, por las vías del diálogo, que aún no se presenta porque a pesar del dispositivo militar gigantesco, las operaciones irregulares de grupos armados delincuenciales logran romper los cercos y cumplir sus objetivos.

En décadas pasadas, muchos colombianos emigraron hacia Venezuela en búsqueda de trabajo en razón de las buenas condiciones económicas del vecino por la bonanza petrolera; ellos contribuyeron sobre todo en las labores del campo y en la dirección de algunas empresas, pues no fueron pocos los cerebros fugados que dejaron su país ante ofrecimientos de salarios difíciles de percibir en Colombia. Sin embargo, la situación social para estas personas se volvió difícil, pues su salario generalmente fue más bajo que el corriente y no eran sujetos de seguridad social. Su situación de migrantes ilegales los convertía en ciudadanos de tercera categoría y fueron muchas las ocasiones de las deportaciones masivas después de detenciones y malos tratos, perpetrados en el pasado por la temible Guardia Nacional. Algunos de estos colombianos que habían emigrado desde la segunda mitad del siglo XX, apenas resolvieron su situación gracias a las políticas del gobierno de Hugo Chávez que ha ofrecido soluciones tangibles. Ahora, una buena parte de ellos son ciudadanos venezolanos y datos sin confirmar dan cuenta de dos millones de colombianos que forman parte del Movimiento Bolivariano que apoya a Chávez en sus iniciativas políticas y sociales. 
Los problemas de orden político-cultural: están representados principalmente por la división del Pueblo Guajiro que se desplaza indistintamente en cualquiera de los dos países en búsqueda de recursos para su subsistencia y cuya mayoría tiene doble nacionalidad y, los indocumentados que representaron el mayor inconveniente socio-económico en la región ya que la mayoría pertenecían a la condición social más baja de los dos países y en ella se agrupaban algunos extranjeros de trabajo itinerante, dedicados a las labores agrícolas, a los servicios domésticos, al comercio informal entre otros. Los malos tratos a que han sido sometidos ciudadanos de los dos países, han causado malestar en la zona de frontera que se traduce en reclamos para que los Estados hagan presencia efectiva e impidan las violaciones de los derechos humanos de sus ciudadanos y los atropellos territoriales. Por tradición los estados con democracias en etapa de consolidación asumen que la presencia estatal se resuelve con la acción policial o las operaciones militares episódicas, dejando de lado las soluciones de índole socioeconómica.

Como se comentó, la zona fronteriza colombo-venezolana permanece en constante tensión política, por los problemas de delimitación pendientes entre las dos naciones y por la delicada situación que enfrenta el gobierno Colombiano con la guerrilla desde hace más de cincuenta años, con repercusiones en ambos lados de dicha frontera. Generalmente en Venezuela en décadas pasadas, algunos gobernantes trataron de despertar el falso nacionalismo, más conocido como patrioterismo para disfrazar anómalas situaciones políticas, sociales o económicas internas. La historia de estos dos países está llena de reclamos, escaramuzas, conflictos y alertas de ataque y defensa. En las hipótesis de guerra de los dos países hermanos, la prioridad siempre ha sido su vecino y en ocasiones las tropas han tomado posición en el terreno en espera del día "D". Los dispositivos de las Fuerzas Militares de los dos países, están montados y sufren reajustes continuamente dependiendo de las informaciones de inteligencia sobre cambios en la situación del hipotético oponente.

Es normal que en la zona de frontera de la Guajira especialmente, los pobladores sintonicen estaciones de radio y de televisión de Venezuela, sometiéndose inconscientemente a procesos de aculturación. Tal vez en Colombia no se tenga claro que una de las principales formas de ejercer soberanía, es mediante el uso del espectro radioeléctrico. En la frontera del departamento de Norte de Santander, tradicionalmente muchos niños venezolanos asistían a clases en escuelas colombianas por comodidad y distancias. Es posible que con las nuevas políticas generadas por el actual gobierno de Venezuela y sus misiones para mejorar la educación, esa situación esté cambiando. Otro problema que también caracteriza la zona fronteriza es la presencia de enfermedades de alto riesgo que suelen propagarse hacia los dos países.

Por fortuna el gobierno actual de la República Bolivariana de Venezuela, ha mostrado marcado interés en la solución racional del diferendo; en 1995 el precandidato a la presidencia 
Hugo Rafael Chávez Frías dijo textualmente a quien esto escribe: "el problema de la demarcación marina debemos solucionarlo como hermanos y si es necesario, explotaremos las riquezas entre los dos países, pero debemos acabar las escaramuzas que nada bueno han dejado". En esta época (2007) aún lo escucho decir lo mismo en su programa Aló Presidente. Es conveniente entonces que Colombia adopte una posición semejante con miras a dar por terminado este diferendo que se ha constituido en un motivo de discordia y de conflicto en una de las más importantes fronteras de América Latina.

\section{Relaciones Bilaterales Colombo-Venezolanas}

Las relaciones bilaterales entre Colombia y Venezuela han abarcado, entre otros, aspectos muy importantes como la integración, el intercambio comercial, el desarrollo fronterizo, la seguridad, la cooperación judicial, la lucha contra el tráfico ilícito de drogas y delitos conexos, la problemática de la doble nacionalidad y la migración ilegal. Estas relaciones presentan características muy particulares y poco usuales entre los países de la región, debido a la gran diversidad de factores que las mismas involucran y por constituir su frontera de 2.219 kilómetros, una de las más extensas y activas del hemisferio. El intercambio comercial entre los dos países en el año 2007 asciende a 5.500 millones de dólares.

En los últimos años, estas relaciones se han visto seriamente perturbadas por la agresión violenta de grupos armados que operan impunemente en zonas limítrofes. Venezuela vive de manera continua acciones delictivas de grupos que pertenecen al narcotráfico, la guerrilla, los paramilitares, la delincuencia y el bandolerismo, que desafían permanentemente el entendimiento civilizado y la convivencia pacífica en la frontera de dos países vecinos, y violentan el desarrollo y la vida cotidiana de sus habitantes. Generalmente, estas actividades delincuenciales constituyen motivo de retaliación pero no contra los reales causantes y sí en contra de humildes campesinos que habitan la región y que se encuentran por lo menos entre dos fuegos. Por desgracia, mientras la prensa muestra evidencias de los vejámenes y atiza los falsos nacionalismos, los altos funcionarios de los dos Estados, niegan la realidad o hacen acusaciones en términos extra diplomáticos, asumiendo la posición de víctimas.

\section{Acuerdos bilaterales}

Los Gobiernos de Venezuela y Colombia en diferentes oportunidades y con el fin de buscar soluciones a los asuntos pendientes, decidieron que serían objeto fundamental del dialogo político bilateral algunos temas preseleccionados. En tiempos recientes y en virtud de ese interés, en reuniones permanentes firmaron el acta de San Pedro Alejandrino el 06 de marzo de 1990, donde definieron como asuntos prioritarios de su relación bilateral, las cuencas hidrográficas y los ríos internacionales, demarcación de fronteras terrestres, delimitación de 
áreas marinas y submarinas, las migraciones, el transporte internacional, la utilización de los recursos naturales que se encuentran en la frontera, y la cooperación y asistencia mutua en casos de catástrofe y calamidad.

En los últimos ocho años desde la llegada al poder de Hugo Chávez, las guerrillas colombianas han tratado de influir en las relaciones políticas de los dos países, pregonando una gran admiración y estrecha amistad con el mandatario venezolano y aunque no han logrado su cometido como parte de su estrategia contra el gobierno colombiano, no han sido pocos los incidentes en los que las cancillerías de los dos países han tenido que salir a desmentir versiones de la prensa amarillista, situación de mala de medios que, reproducen noticias en forma irresponsable. Los paramilitares también han puesto su cuota dañina en estas relaciones y han perpetrado acciones delictivas comprobadas, llegando incluso a incursionar en Caracas como parte de un diabólico plan de la oposición venezolana de desestabilizar su propio país. Para los días que este artículo escribo, el Presidente Hugo Rafael Chávez Frías, propició el indulto de un grupo de paramilitares colombianos que habían sido apresados como responsables de un intento de apoyo armado a la oposición venezolana.

\section{Causas de Tensión Fronteriza}

Además del inconformismo por la delimitación de áreas marinas, la frontera colombo-venezolana es desde hace varios años un foco de tensión bilateral y de violencia, materializada al penetrar grupos rebeldes colombianos a territorio de Venezuela para secuestrar personas, robar aviones, lanchas, vehículos y atacar puestos fronterizos, además del tradicional contrabando y tráfico de drogas. Las agresiones armadas por parte de criminales de derecha y de izquierda, contra civiles y militares, es cada día más grave y preocupante. Al número de soldados y civiles venezolanos y colombianos muertos y heridos, víctimas de la acción armada de la narcoguerrilla de izquierda y de derecha, hay que sumarle el hostigamiento diario que se comete contra la vida productiva económica y social de la región, contra trabajadores, productores comerciantes y empresarios secuestrados y chantajeados con pago de vacunas y rescates, a cambio de sus vidas y las de sus familiares.

En los últimos tiempos se han conformado bandas de delincuencia con ciudadanos de los dos países, dedicadas especialmente al robo de automóviles, secuestro, extorsión, narcotráfico, tráfico de armas y pertrechos militares. Especialmente a partir del año 2003, la aviación comercial del vecino país se ha visto diezmada por acciones de la Fuerza Aérea Colombiana que ha derribado varios aviones pequeños venezolanos acusados de llevar cocaína de Colombia a otros países. Las estadísticas de las autoridades colombianas muestran que año tras año las operaciones aéreas no autorizadas desde Venezuela se han intensificado hacia territorio de Colombia para el transporte de narcóticos, armas y municiones. Es apenas lógico supo- 
ner que estas actividades delincuenciales son realizadas por bandas organizadas y no cuentan con el aval de las autoridades. Sin embargo, queda la duda sobre los controles que ejercen las mismas y la eficiencia de los dispositivos militares de los dos lados de la frontera.

\section{La Guerrilla y el Narcotráfico}

Aunque este ha sido un problema interno de Colombia, el mismo ha desbordado sus propias fronteras y para el caso específico de Venezuela, estos grupos delincuenciales de izquierda y de derecha, operan en la zona limítrofe, creando nuevas fuentes de tensión y conflicto por los continuos hechos violentos que perturban la estabilidad y la paz social nacional. Venezuela se ha quejado del abandono de estas áreas por parte del gobierno colombiano y este a su vez, se queja cuando el Ejército del país vecino penetra tierras colombianas en persecución de delincuentes. Es la violencia que envuelve la vida en la frontera; la presencia de guerrilleros en Venezuela no es nueva y actualmente también preocupa la presencia de paramilitares actuando en la región para explotar criminalmente lo que se ha denominado las industrias ilícitas. El narcotráfico fue una amenaza particular para Colombia pero su accionar ha crecido de manera alarmante por el apoyo logístico que recibe de las guerrillas y los paramilitares asentados en zonas rurales fronterizas, a pesar de los esfuerzos realizados con ayudas bilaterales y multilaterales. En los últimos años, esta frontera ha sido utilizada para sacar droga de Colombia hacia Venezuela como puerto de exportación a los Estados Unidos y Europa, vía aérea o marítima o para el intercambio por armas.

Los carteles de la droga han conformado toda una industria del delito, apoyada en la organización que tienen la guerrilla y los paramilitares. Estos ha asumido todas las funciones que van desde la siembra hasta la exportación y comercialización en dólares o el canje por armas. Esta industria criminal se ha transformado en una transnacional con capacidad de corrupción sobre instituciones y personajes de otros países como el reconocido Vladimiro Montesinos en Perú y Fernandiño en el Brasil, quienes fueron socios de las FARC y les ayudaron a comprar grandes cantidades de armas y pertrechos militares. Actualmente Montesinos es procesado en Colombia por el apoyo a las FARC en la compra de 10.000 fusiles que fueron negociados en Europa y lanzados en paracaídas en territorio limítrofe colombo-venezolano.

Diversos ataques y emboscadas a puestos fronterizos venezolanos, el terror sembrado en productores del campo venezolano y colombiano y la destrucción del ecosistema de algunos parques nacionales protegidos por el Estado, en los que se han detectado sembradíos de amapola a lo largo de los años, son ingredientes que generan mayor tensión.

Otro problema coyuntural generado por el conflicto interno colombiano es la situación de los desplazados; Venezuela ha recibido solicitudes de refugio en varias oportunidades y en una 
ocasión el problema se suscitó con una población entera de aproximadamente 3.500 campesinos que huyeron al estado del Táchira por los ataques de la guerrilla en su territorio. Esta situación está ligada al tema de los derechos humanos, pues en repetidas ocasiones, la población civil ha sido víctima de guerrillas y paramilitares por su supuesta participación en el conflicto. No hay que olvidar que según cifras establecidas por organismos internacionales, en Colombia el número de desplazados, supera los dos millones y medio de personas.

\section{Presencia Militar en la Frontera:}

En el marco de las soluciones concertadas entre Colombia y Venezuela se ha insistido prioritariamente en la necesidad de reforzar militarmente la zona fronteriza común, debido a que la narcoguerrilla y los narcoparamilitares actúan en esta área a su anchas, aunque de diferentes maneras pero igualmente su accionar criminal afecta la política de los dos países e incluso se ha hablado de la posibilidad de permitir la persecución de facinerosos de ambos lados de la frontera, es decir por parte del gobierno Venezolano y del Colombiano. Esta tesis tomó el nombre de persecución en caliente pero no prosperó por asuntos relacionados con el derecho internacional. No obstante, no se puede negar que las relaciones fronterizas continúan siendo perturbadas por la persistencia de fenómenos de violencia.

La Fuerza Armada Nacional Venezolana (FAN) ha incrementado su presencia en la frontera que comparte con Colombia, con el fin de repeler ataques de los grupos guerrilleros de las FARC y del ELN, así como de los paramilitares que tienen campamentos en territorio Venezolano. El ejército venezolano en 1.999 contaba con 20.000 militares distribuidos en 105 puestos a lo largo de la frontera de 2.219 kilómetros para frenar la acción de contrabandistas y del hampa común. A partir del año 2002 esa cifra se ha incrementado en forma logarítmica, pero sólo ellos conocen las cifras exactas.

A partir de la década del 80 del siglo pasado Colombia ha reajustado su dispositivo militar en forma permanente, pero a partir de la década del 80 del siglo pasado con mayor énfasis. Se activó la Primera División del Ejército con sede en Santa Martha, la Segunda División con sede en Bucaramanga, la Brigada No. 17 en Arauca, la Brigada Blindada en la Guajira, el Comando Aéreo de Combate en Barranquilla, se instalaron radares en la Guajira, se activó un batallón de infantería mecanizada, la Armada Nacional mejoró sus recursos y activó la aviación naval; en fin, el mejoramiento de las Fuerza Militares Colombianas ha dependido de su situación política interna y de la situación política de Venezuela y de los cambios en el aparato militar de su potencial enemigo. Definitivamente los que ganan con estas locuras son las grandes empresa que venden armamento y equipó militar, especialmente norteamericanas, israelíes, brasileras, surafricanas, rusas, chinas, alemanas y otras europeas. 


\section{Chávez respalda el proceso de paz en Colombia}

Venezuela apuesta al proceso de paz en Colombia como la mejor forma para resolver un conflicto que no le es ajeno ni por los secuestros y extorsiones de delincuentes colombianos en contra de hacendados venezolanos en la frontera, ni por las recientes amenazas de los paramilitares colombianos. Al facilitar su territorio para encuentros del Ejército de Liberación Nacional (ELN) con el gobierno y con la sociedad civil, el presidente Hugo Chávez ha ratificado su intención de convertirse en protagonista del proceso de paz que se realiza en Colombia. Lo motiva el interés por resolver un conflicto que podría terminar contaminando a Venezuela pero también su deseo de catapultarse como líder regional. Chávez se opone firmemente a una intervención militar en Colombia por dos razones: 1- el temor a la agudización del conflicto 2- el riesgo de desestabilización política en Venezuela con efectos colaterales en otros países de la región. A partir del mes de agosto del año 2007 el Presidente Chávez pasó a ocupar los titulares de los principales diarios del mundo por su nuevo papel de mediador para un posible intercambio humanitario entre secuestrados por las FARC y presos de esa agrupación irregular, propuesto por el gobierno de Colombia.

\section{Ecuador: Un respeto a la tesis de no intervención}

Esta frontera se extiende a lo largo de 586 kilómetros, los cuales sirven de límite entre dos departamentos y trece municipios en Colombia y tres provincias y veinte municipios en Ecuador.

Algunos hechos relevantes entre estos dos países son los siguientes: en 1916 se firmó el Tratado Suárez-Vernaza que fija límites terrestres y marítimos. En 1989 se hace pública la Declaración Barco-Borja para crear la Comisión de Vecindad e Integración. En 1990 se firmó el Convenio sobre tránsito de personas, vehículos y embarcaciones. En 1996 se creó la Comisión Binacional de Fronteras (COMBIFRON) para el intercambio de información e inteligencia militar. En 1998 se activó el Comité Binacional de Control, Seguridad y Vigilancia Fronteriza. En 1998 se firmó el Acuerdo sobre Derechos Humanos, Asentamientos en Frontera y Asuntos Laborales y Migratorios. En 1999 los paramilitares asesinaron en Ecuador al diputado de izquierda, Jaime Hurtado, invitado por las FARC al Caguán. En septiembre 11 del mismo año un grupo armado secuestró en la provincia ecuatoriana de Sucumbíos a 12 europeos y al ser acusadas, las FARC negaron su autoría. El 11 de enero del año 2001 se presentó un enfrentamiento armado entre militares ecuatorianos y guerrilleros colombianos en Puerto El Carmen. Ese mismo año, el 25 de enero, las FARC atacaron por cuarta vez el Oleoducto Transecuatoriano en la vía Lago Agrio-Balao. En febrero 23 del mismo año fuerzas capturaron un guerrillero de las FARC intentando comprar armas en Quito. En noviembre de 2002, se desmanteló un campamento guerrillero en Bermejal. En noviembre 19 se capturó en Ecuador 
una banda procedente de Colombia con 2,4 toneladas de coca; de la banda formaba parte un coronel ecuatoriano. En el año 2007 han continuado las escaramuzas entre los dos países por actividades de las FARC y de los paramilitares tanto en la frontera como en territorio ecuatoriano.

A finales de la década del 90 fueron retirados los pocos destacamentos militares de Colombia ubicados en la frontera -en Candelilla de la Mar, en el Pacífico, y otro en Puerto Ospina, sobre el río Putumayo-. Varios ataques de las FARC contra guarniciones como Las Delicias y Coreguaje en Putumayo y Puerres en Nariño, llevaron a los militares colombianos a cambiar de táctica. "No queremos tener bases fijas, están revaluadas. Nuestro sistema operativo es móvil", había dicho entonces el general Carlos Alberto Fracica, director de Inteligencia del Ejército Nacional de Colombia.

Pese al esfuerzo de las autoridades por bajar los índices de criminalidad en las ciudades fronterizas ecuatorianas, se dispararon las actividades de narcotráfico; así lo demostró el decomiso de unas 20 toneladas de cocaína en la costa pacífica colombiana y la destrucción en el año 2002 de cinco campamentos de la guerrilla en territorio ecuatoriano, uno de ellos, según el comandante de la cuarta División del Ejército Ecuatoriano, con capacidad para albergar a 400 hombres y con sistemas de comunicación satelitales. Sin embargo, la fórmula estaba lejos de ser perfecta, entre otras, por la desconfianza que existe entre las fuerzas militares de las dos naciones. A pesar de que la COMBIFRON con Ecuador -esquema de cooperación militar- fue la primera en entrar en funcionamiento, uniformados colombianos aseguraban en ese tiempo que no había tenido mayor fluidez e incluso había quienes dudaban en compartir información por los escándalos en los que aparecieron involucrados algunos militares ecuatorianos. Escándalos que citaban presuntos tráficos de armas y municiones para las FARC. La relación entre los dos países ha pasado por tiempos azarosos.

El repentino y frecuente cierre del puente fronterizo, en el paso de Rumichaca, el pedido de mantener una faja de 10 kilómetros en la que no se fumiguen cultivos ilícitos, la incomodidad por los desplazados colombianos copando las calles y los brotes de xenofobia son síntomas de descontento entre los ecuatorianos. Pero existen también factores que han contribuido a amortiguar esos efectos de la guerra: unos férreos vínculos históricos entre las poblaciones indígenas y negras de las dos naciones y una relación de fraternidad entre los habitantes de la frontera, al igual que un intercambio comercial de casi 1.200 millones de dólares al año, que hace de Ecuador el tercer socio comercial de Colombia.

Según la Cancillería colombiana, es en esa frontera donde la tarea de integración está más avanzada. A diferencia de lo que no se ha logrado con los otros vecinos, ya se dio inicio al Plan de Desarrollo Binacional -establecido por canje de notas diplomáticas -que debe llevar a una legislación común en cuanto al uso de todo tipo de bienes y servicios y a la convalidación de estudios, entre otras actividades. 
Desde la Constitución de 1991, Colombia ha avanzado de manera significativa en una legislación en favor de las minorías étnicas. En los últimos 35 años el Estado ha destinado 234 mil millones de pesos para la adquisición y mejora de tierras indígenas. La ley 715 del 2001 determinó entregar a los resguardos el 0,52 por ciento de las transferencias. En el año 2002, se les asignaron 57.300 millones de pesos. Pero, como lo acepta Planeación Nacional, en el documento Los Pueblos Indígenas de Colombia (2002) -el estudio más reciente y completo sobre la cuestión- "las políticas públicas en materia de indígenas no suelen considerar a los que viven en las zonas de frontera". Se ha ampliado la cobertura en educación primaria, pero la pobreza es tal que la deserción es muy alta, y hay quejas porque la educación no tiene en cuenta las particularidades indígenas.

Con el 70 por ciento de selvas y sabanas casi intactas, los territorios indígenas fronterizos ocupan, según constata Planeación, "el mayor remanente de ecosistema originario y de biodiversidad" sujeto a presiones colosales. Buscadores de oro en el Guainía, petróleo en Putumayo y Arauca, tala de madera en Chocó y Amazonas, vastos frentes cocaleros que avanzan desde Guaviare y Caquetá hacia Vichada y Vaupés, todos ellos se combinan con abusos de los grupos armados, reclutamiento, desplazamiento, miseria y abandono inmemorial de la población.

En la frontera colombo-ecuatoriana el panorama es crítico y en los últimos años los problemas se han incrementado. El ejército ecuatoriano disponía en 1999 de aproximadamente 400 hombres en un batallón de infantería en la fronteriza ciudad fronteriza de Tulcán y dos compañías en El Oro y Lago Agrio. En esa zona opera el bloque sur de las FARC, que utiliza la frontera para el tráfico de insumos, drogas, explosivos y armamento. Las fumigaciones a cultivos de coca y amapola en esta zona no han solucionado la situación y el presidente Rafael Correa impetró una denuncia en la Haya contra Colombia por los daños colaterales, fumigaciones que según se afirma, no acaban con los cultivos ilícitos y si con las siembras de pancoger de los campesinos ecuatorianos. Continuas notas entre las cancillerías han tenido lugar entre 2006 y 2007 sin que la solución definitiva al problema se avizore.

\section{La tesis de neutralidad de Ecuador}

En Ecuador ha hecho camino la tesis de la no intervención en Colombia y menos la intención de adherirse a ningún plan continental para atacar a la guerrilla. El gobierno ecuatoriano, había dicho que lo único que haría, sería reforzar la vigilancia militar en la frontera para evitar que cualquier grupo armado, sea insurgente, delincuencial o paramilitar, tratara por diversos modos de penetrar el territorio ecuatoriano. Y es que más allá de lo formal, el Ecuador no deseaba verse involucrado, de ninguna manera, en un conflicto al que teme. Sin embargo, muchos críticos opinaron que al permitir una base estadounidense en Manta, ya se había involucrado. 
Los secuestros en territorio ecuatoriano exasperaron los ánimos. A raíz del plagio de 12 extranjeros en 1999 veinticuatro horas después, Venezuela también reacciono. El alto gobierno del vecino país anuncio que todo colombiano que aspire a trabajar en fincas o empresas en su territorio será carnetizado. La medida pretendía evitar la infiltración de guerrilleros y garantizar la seguridad en el área. Pero más allá de las amenazas de Carlos Castaño -jefe de los paramilitares- de las incursiones de las FARC en la Amazonia ecuatoriana y del miedo que estos actos produjeron entre la población, surge una pregunta: ¿Colombia y sus vecinos están en capacidad de controlar 6.341 kilómetros de fronteras naturales y contrarrestar la amenaza paramilitar y guerrillera?

"Es imposible para Colombia y para cualquier país vecino hablar de un control del cien por ciento de las fronteras, cuando esos lugares son selváticos, las condiciones y la lejanía del territorio no permiten que haya grandes bases militares y menos, apoyo rápido y eficaz" (CADENA: 1999). Germán Castro García y Jorge Puentes Soto, militares en retiro, en un documento titulado "Los verdaderos responsables de la inseguridad nacional", afirman que Colombia nunca se ha preocupado por desarrollar una infraestructura que le permita defender dignamente sus fronteras. "es evidente que ante los desafíos de la subversión no hay dinero para la defensa ni para las obras de frontera que nos permitan mantener nuestra dignidad".

A juicio del general Rafael Hernández López, jefe del Estado Mayor de las Fuerzas Militares de Colombia en 1999, "cada país debe responder por la seguridad de su área limítrofe". Pero la realidad es, según dicen otros expertos, que el accionar de paramilitares y guerrilleros en zonas de frontera supera la capacidad de los estados para proteger sus líneas divisorias. Al comenzar el nuevo milenio (2000) en los más de 6.000 kilómetros que Colombia compartía con sus países vecinos operaban 71 frentes guerrilleros -con cerca de 15.000 combatientes- y 45 grupos de autodefensas -que totalizaban cerca de 12.000 efectivos-(HERNÁNDEZ:1999). Esta amenaza armada, unida al narcotráfico y al creciente accionar de la delincuencia común pretendía ser controlada, en el caso colombiano, por menos de 30.000 efectivos militares y policiales. Esta fuerza estaba dotada con fusiles, morteros, cañones de limitado alcance y no más de 100 vehículos, a los que escasamente se les hacía mantenimiento. Eso sucedía a finales de la década de 1.990 pero la activación del Plan Colombia propició la llegada de nuevas armas, helicópteros, lanchas, vehículos terrestres y activación de nuevas unidades de soldados profesionales.

Cuando el presidente Lucio Gutiérrez llegó al poder en el 2003, Ecuador pasó a ser, entonces, aliado de la estrategia estadounidense y colombiana, al aceptar la consolidación de una base militar extranjera y al insertar su futuro dentro de la visión de Estados Unidos para la región. Los tres últimos gobiernos respondieron con mayor militarización en la frontera con Colombia, cuyo pie de fuerza militar superaba en el 2003 los doce mil hombres, la más alta cifra de 
concentración de tropas en la historia de Ecuador. El centro gravitacional estratégico de las Fuerzas Armadas Ecuatorianas había sido desplazado a Colombia de manera irreversible. A pocos kilómetros de allí, en la Amazonía brasileña, los Estados Unidos pretendieron apoderarse de la base de Alcántara, pero el gobierno local se resistió a cederles esa zona y la controlan ellos mismos.

Ecuador activó un Plan de Defensa Interna que pretendía ubicar 10.000 efectivos más y una unidad helitransportada a menos de 100 kilómetros de la frontera. Para ello, los Estados Unidos también donaron 18 helicópteros en el marco de la Iniciativa Regional Andina. El sistema parece haber logrado algún control gracias a que los batallones móviles antinarcóticos del Plan Colombia han estado operando en la zona. Cuando terminen de asentarse los nuevos soldados ecuatorianos y sus equipos, habrá que revisar entonces si la presión de Estados Unidos y la colaboración de Colombia y Ecuador habrán logrado cambiarle la cara a la frontera y darle un giro al que hasta ahora es considerada el eslabón más débil del vecindario.

\section{Brasil: si hay problemas fronterizos pero no son nuestros}

Los 1.645 kilómetros de frontera limitan con tres departamentos y cinco municipios en Colombia y un estado y cinco municipios en Brasil. El concepto de la cancillería brasileña resume así la visión de su país: "Para nosotros, lo que hoy es Ilamado como problema colombiano es sin duda un problema, pero está lejos de ser considerado una amenaza para nuestro país". La idea oficial es que se trata de un problema interno y debe ser resuelto por los colombianos. Brasil se opone tajantemente a cualquier forma de intervención militar en Colombia y ya le anunció a los Estados Unidos que únicamente intervendrá con fuerzas de paz -no de combatesi el gobierno colombiano claramente así lo pide. Brasil se niega a ser empujado a una guerra en la que, dicen, "seria fácil entrar pero difícil salir" y se opone a patrocinar un mayor intervencionismo estadounidense.

Completa el cuadro de los efectos del conflicto colombiano la tragedia de los refugiados, cuya magnitud, objeto de diversas estimaciones es, en cualquier caso, notable y creciente y ha generado peligrosos procesos de xenofobia. La respuesta ha sido un aumento notable en el pie de fuerza fronterizo del vecindario, en parte gracias a la Iniciativa Regional Andina. Con los cinco países limítrofes, Colombia ha organizado las llamadas COMBIFRON, dedicadas al problema de seguridad. Brasil se ha blindado por su cuenta y está estrechando la cooperación. Sin embargo, la actitud reactiva y la desconfianza mutua son la norma, por lo tanto, es urgente diseñar e implementar una política de seguridad regional, construyendo una verdadera política de fronteras.

Insisten, como lo dijo un alto responsable de inteligencia, en la necesidad de una ley de seguridad de fronteras. Puede debatirse qué tan grande es la amenaza que el conflicto 
colombiano representa para la región. Pero una cosa parece fuera de toda duda: las fronteras siguen siendo lugares lúgubres y después de casi un siglo de abandono, hoy es, paradójicamente, la guerra la que las está sacando del olvido.

En lo militar Brasil dispone de una brigada en la población de Tabatinga, con 8.000 militares aproximadamente, cuatro bases aéreas relativamente cercanas y un puesto fluvial en el Amazonas. Con esta fuerza controla las esporádicas incursiones de la guerrilla, que utiliza la frontera para el tráfico de armas, de material de intendencia, drogas y alimentos. Estos destacamentos fronterizos dependen de Manaos, la capital del estado brasileño de Amazonas.

Tabatinga es la última escala, el último punto limítrofe brasileño con Colombia, en el extremo sur de los 1.640 kilómetros de frontera común. Una desdibujada callejuela, la separa de Leticia, capital de la provincia de Amazonas en Colombia. Entre las dos hay un abismo cultural. Del lado brasileño solo se habla portugués, del colombiano, español. Los 30 mil habitantes de esta ciudad -que se completan con 10.000 indígenas- tienen cuatro fuentes de empleo: la Alcaldía, las Fuerzas Armadas, la Policía Federal y el narcotráfico. Unas 2.000 personas viven de la explotación pesquera, aunque también transportan droga escondida dentro de las barcazas. En el año 2002 tropas especiales del ejército fueron desplegadas desde Río de Janeiro para combatir al narcotráfico. Se trataba de 1.100 hombres especialmente reclutados de las principales unidades dentro de esa fuerza, denominada Brigada de Operaciones Especiales (BOPE), con sede en Goiania con poder de policía para realizar acciones de comando, antiguerrilla.

El principal aporte brasileño al negocio del narcotráfico son los pilotos y la flota aérea. En bimotores se transporta la cocaína pura hacia el Atlántico. Los aviones cruzan la selva del Amazonas, con escalas en pistas clandestinas brasileñas, hasta Surinam, la ex colonia holandesa. De Surinam, poblado por 300.000 habitantes, la droga sale en los barcos cargueros holandeses, que abastecen el consumo europeo. ¿Por qué Holanda no los reprime? Hay un problema político: Surinam vive del comercio con Holanda. El ingreso del país es de U.S. \$ 1.400 millones al año que provienen en $90 \%$ del tráfico de droga. Este es un caso típico de la nueva geopolítica que muestra como el desarrollo continuo de la economía global terminará

por socavar el Estado-Nación y favorecerá la región. Esto representa un anatema para aquellos que creen que un estado grande, centralizado, es la única vía para dirigir la política, la sociedad, la economía y la cultura (OHMAE: 2005).

\section{Perú: Una extensa y selvática frontera en el abandono}

Con una extensión de 1.626 kilómetros, dos departamentos y tres municipios de Colombia, un departamento y dos municipios del Perú, población peruana de 919.505 personas y colom- 
biana de 436.371 esta selvática frontera presenta las condiciones favorables para construcción de pistas clandestinas y comercio de insumos para el procesamiento de drogas ilícitas.

En tiempos del presidente Alberto Fujimori se tomó en serio la "amenaza" que representaba el conflicto interno que vive Colombia y en tal virtud incrementó de 100 a dos mil los militares que aseguraban la frontera después de los acuerdos de paz con Ecuador. El gobierno peruano justificó la movilización por la posibilidad de que el problema colombiano se desbordara. Sin embargo, algunos analistas, dijeron en ese tiempo que el Gobierno sobredimensionaba el tema, para garantizar el protagonismo de los militares, quienes habían pasado a un segundo plano luego del acuerdo de paz con Ecuador.

Otros argumentaban que gracias a la estrategia anti subversiva de Fujimori, Perú se había salvado de llegar a los niveles de violencia que hoy azotan a Colombia. El asunto fue favorable para Fujimori quien preparaba su segunda reelección. El 63\% de la población apoyó las medidas de protección de las fronteras.

El gobierno de Perú cuenta con un puesto fluvial, tres batallones de infantería y un grupo de artillería cercanos a la frontera que dependen de una división de selva en Iquitos. En total, Perú tiene 2.500 militares en la frontera con Colombia, incluyendo una compañía de la Guardia Republicana. En la frontera peruana está latente la amenaza del bloque sur de las FARC y las incursiones continuas de las bandas de narcotraficantes de ambos países que han sido socios por muchos años.

La selva amazónica en esta frontera tiene dos caras. Una es la del turismo de aventura, del que gozan americanos y europeos, cansados de la vida confortable en sus países de origen. Otra es la de la miseria y la violencia que sufren, día a día quienes viven en la región en forma permanente.

\section{Panamá: Con muchas amenazas y sin ejército}

Con una extensión de 225 kilómetros, su frontera va del Atlántico al Pacífico; Los límites con Colombia se materializan por un departamento y tres municipios, y por Panamá con dos departamentos y cuatro municipios. Esta frontera es un caso especial. Ese país no tiene ejército y el control ciudadano está a cargo de 1.500 hombres de la Guardia Nacional.

Las actividades más relevantes entre los dos países pueden resumirse así: en 1903 Panamá se separó de Colombia. En 1914 se celebró el Tratado Urrutia- Thompson, por el cual Colombia reconoció la independencia de Panamá. Estados Unidos se comprometió a pagar a Colombia 10 cuotas de 250.000 dólares cada una. En 1924 se firmó el Tratado Vélez-Victoria que delimitó 
la frontera terrestre. En 1976 se legalizó el Tratado Liévano-Boyd, sobre límites marítimos. En 1992 se firmó un acuerdo mediante el cual reconoció Panamá a los refugiados colombianos la figura de 'protegido humanitario' temporal. En marzo del mismo año se creó la Comisión de Vecindad Colombo-Panameña. En 1997 primero de abril las FARC asesinaron a cuatro personas en La Bonga y Titiná (Panamá). En noviembre 15 del mismo año, las FARC asesinaron a un policía en Boca de Cupe. En 1998, se firmó el Acuerdo de Asistencia Mutua sobre Tráfico de Estupefacientes. En 1999 abril 20 las FARC atacaron la población de Sapzurro. En noviembre del mismo año, paramilitares hostigaron a la Policía panameña en el hito fronterizo. En diciembre 12 una cruenta toma de las FARC a Juradó provocó un masivo éxodo de civiles a Jaqué (Panamá). En octubre del 2000 las FARC atacaron La Darienita de Nazaret (Panamá). Entre septiembre y octubre descubrieron en Panamá varios arsenales destinados a Colombia. El 18 de diciembre de 2002 los presidentes de los dos países acordaron reiniciar reuniones bilaterales. El 18 de enero de 2003, grupos paramilitares asesinaron a cuatro autoridades indígenas kuna, en las aldeas fronterizas de Paya y Pucurú. El 11 de abril del mismo año, se firmaron por funcionarios de los dos países la Directiva y el Manual de Procedimiento Operativo de la COMBIFRON. El 21 de abril del mismo año, 109 desplazados colombianos fueron deportados desde Panamá a Colombia.

Entre 1999 y 2004 Panamá fue gobernada por Mireya Moscoso quien reemplazó a Ernesto Pérez Balladares y una de sus primeras acciones de gobierno fue recorrer la frontera con Colombia. La visita a la frontera de la recién posesionada presidenta panameña, demostró que este vecino estaba realmente preocupado por la creciente penetración de guerrillas y paramilitares colombianos en su territorio. Moscoso anunció entonces que se reforzaría los 1.500 policías que cuidaban la frontera -este país no cuenta con ejército desde la invasión de Estados Unidos en 1989- pero las autoridades panameñas saben que carecen de pertrechos y entrenamiento para tener una fuerza con capacidad de defender la frontera y por eso insisten en una mayor presencia de las Fuerzas Armadas colombianas. Lo que más preocupaba en ese entonces a nivel interno, era que el tema pudiera ser utilizado para justificar la continuidad de las tropas de Estados Unidos más allá del mes de diciembre de 1999 cuando debería hacerse efectiva la devolución del Canal.

El 31 de diciembre de 1999 al medio día, Panamá asumió la administración de la vía interoceánica. En el edificio de la administración del canal se congregó el cuerpo diplomático acreditado en ese país, además asistieron, con grandes muestras de patriotismo, diversas organizaciones populares. Esto dio origen al nuevo Ministerio de Estado para Asuntos del Canal. Los gobiernos de Colombia y Panamá realizaron una cumbre bilateral y se comprometieron a velar por la seguridad de su frontera común. La reunión y la movilización de tropas se convirtieron en la respuesta a la amenaza de Carlos Castaño Gil, líder de las autodefensas, de convertir en objetivo militar a los miembros de la Guardia Nacional de Panamá que apoyaran a 
las FARC. En el año 2006 las FARC le enviaron una carta al presidente Martín Torrijos en la que lo felicitan por su política fronteriza constituyendo este hecho una clara muestra de la actividad diplomática internacional del grupo guerrillero.

\section{DIFERENDO CON NICARAGUA, TOQUE DE CAMPANA}

Además de los problemas conocidos en las cinco fronteras mencionadas, Colombia en la actualidad afronta problemas con Nicaragua por la delimitación de las áreas marinas. El antecedente más antiguo es un tratado suscrito en Managua en 1928 entre los dos países que fue declarado nulo por Nicaragua en 1980 alegando que el mismo se firmó bajo presión cuando el país estaba sometido por la ocupación extranjera. Este Tratado, llamado Bárcenas MenesesEsguerra, fija la frontera en el meridiano 82.

Hoy Nicaragua reclama derechos sobre el Archipiélago de San Andrés y Providencia, además de algunos cayos, que fueron materia de otro tratado entre Colombia y Honduras en 1.986. La historia de este diferendo es larga y refleja rasgos característicos de la antigua geopolítica. A continuación, algunos datos necesarios para situar mejor los orígenes y razones del litigio entre Colombia y Nicaragua.

Colombia suscribió con Estados Unidos el 8 de septiembre de 1972 un tratado, conocido como Saccio-Vázquez Carrizosa. Por él, Estados Unidos cedía y traspasaba la soberanía de los cayos y bancos de Roncador, Serrana y Quitasueño a Colombia, poniendo fin de esa manera a lo acordado en las notas Olaya-Kellog. El tratado de 1972 provocó una vehemente reacción en Nicaragua, que de inmediato expresó su firme oposición. A finales de 1979 se abrió paso en la Cancillería de Nicaragua la preocupación por la defensa de los intereses territoriales del país.

La Cancillería nicaragüense Ilevó la querella territorial a la Corte Internacional de Justicia de La Haya, mientras el gobierno colombiano reafirmó su soberanía en la extensa zona y ha manifestado en numerosas declaraciones su derecho a estos territorios. "Quiero dejar el problema resuelto al terminar mi mandato", declaró entonces la Presidenta Chamorro en 1999

mientras técnicos y juristas preparaban el camino para que la resolución sea favorable a Nicaragua.

Ante los reclamos de Nicaragua, la Corte Internacional de Justicia (CIJ) anunció la celebración de una serie de audiencias para examinar sus competencias, cuestionadas por Colombia. La CIJ, es la máxima instancia judicial de la ONU y juzga los diferendos entre los Estados, especialmente, las diferencias territoriales. Sus decisiones son definitivas y sin posibilidad de apelación, pero no está capacitada legalmente para obligar a ningún país a ejecutarlas. 
Colombia impugnó la competencia de este tribunal, una objeción recogida en sus "excepciones preliminares" presentadas en julio de 2003. Antes que nada, la Corte deberá estudiar estas cuestiones de procedimiento, algo que podría tomar un largo tiempo, y únicamente si se declara competente podrá estudiar a fondo el caso.

En concreto, Nicaragua solicitó en diciembre de 2001 al Tribunal que reconociera su soberanía sobre unas islas y territorios marinos en el Caribe Occidental, reivindicadas por Colombia y ricas en petróleo. El Instituto de Energía de Nicaragua anunció la apertura de un concurso para una prospección petrolífera que incluye los territorios disputados. Por su parte, la empresa Nacional de Hidrocarburos de Colombia, ECOPETROL, autorizó a la multinacional noruega INSEIS Ilevar a cabo exploraciones en esta misma zona.

Nicaragua argumentó que un documento firmado en 1803 tuvo vigencia formal durante escasos tres años y que ha servido hasta hoy para que Colombia dispute a Nicaragua islas y cayos que, por geografía y por historia son parte del territorio centroamericano y más específicamente, del territorio nicaragüense, pues se encuentran claramente ubicados frente a sus costas. En litigio están también los límites de la plataforma marina -rica en pesca y minerales- en la que se encuentran estas islas y cayos. Al llegar en el año 2007 por segunda vez a la presidencia de Nicaragua, Daniel Ortega ha iniciado las reclamaciones con vehemencia y actualmente se espera el pronunciamiento de la Corte Internacional de Justicia.

\section{CONCLUSIONES}

1- $\quad$ El desinterés del Estado colombiano por sus fronteras no permite registrar en detalle ni medir los fenómenos fronterizos en el ámbito municipal y departamental como unidad de análisis. Así las cosas, ha sido muy difícil explorar la intensidad y extensión territorial de los fenómenos fronterizos. Sólo malas noticias se conocen en las fronteras colombianas sin que exista una bitácora con índices reales que permita planear una verdadera política fronteriza.

2- $\quad$ La lucha que mantiene Colombia con sus focos guerrilleros desde hace más de cinco décadas, ha traído inestabilidad y una gran cantidad de muertes a lo largo de sus fronteras. A esto se añade la problemática de los paramilitares, los cuales, conjuntamente con las células guerrilleras colombianas han sido catalogados como terroristas por la comunidad internacional; grupos que actúan sin recato alguno, tanto en Colombia como en países vecinos, obligando en gran medida a estos a involucrarse en los problemas internos de Colombia. 
3- $\quad$ A esta altura del conflicto colombiano, es claro que las acciones extraterritoriales de los delincuentes, buscan debilitar al Estado comprometiendo sus relaciones políticas con los vecinos para tratar de internacionalizar el conflicto con miras a obtener dividendos. Se deduce entonces, que a las operaciones militares del Estado en las fronteras les hace falta el análisis político para asegurar la victoria y para el correcto manejo de las relaciones internacionales en la Región Andina especialmente.

4- $\quad$ La prioridad en las relaciones entre gobiernos de países vecinos y Colombia, dentro del marco de la política internacional, se manifiesta en encuentros de presidentes, cancilleres, vicecancilleres y titulares de los respectivos ministerios, adelantando acciones para la búsqueda de soluciones a los problemas que se presentan en las líneas limítrofes, pero la inexistencia de políticas claras para el tratamiento de estos temas, convierten esos encuentros en coyunturales y transitorios sin que en realidad sirvan para sanar viejas heridas y para proyectar la región fronteriza como el escenario de lo que debería ser la puerta de entrada y salida de diferentes actividades entre países hermanos, libertados por la misma espada.

5. La frase utópica de "un mundo sin fronteras" que pregonan quienes creen que la globalización es la solución para muchos problemas del mundo, no es aplicable en Colombia, pues las fronteras en pleno siglo XX se constituyen en los más resistentes muros que aíslan al País de sus vecinos. Y lo peor es que el Estado continúa de espaldas a la realidad.

6- $\quad$ Las operaciones militares fronterizas deben ser un medio y no un fin para lograr el desarrollo y la integración de los pueblos. Militarizar las zonas de frontera tiene sus riesgos porque soldados bien entrenados, listos a vencer, crean una situación de alta tensión en el área y se corre el riesgo de que cualquier persona que sea vista en esa zona se convierta en objetivo militar.

7- $\quad$ La percepción de riesgo regional atribuida al conflicto interno colombiano se expresa en una preocupante escalada de la estrategia militar del Pentágono en la región andina observable por la creación de sendos teatros de operaciones en las fronteras colombianas, la negociación de soportes militares menos evidentes en el área y una campaña psico-social en los ámbitos académicos norteamericanos que permitan el levantamiento de hipótesis realistas y encuadren una intervención en coalición enfatizando la corresponsabilidad subregional sobre el tema.

8- $\quad$ La Orinoquia y la Amazonia colombianas han tenido presencia histórica de las FARC dada su ubicación estratégica para el tráfico de drogas y de armas por los ríos hacia 
Ecuador, Perú, Brasil y Venezuela. Adicionalmente, recibe los efectos de las estrategias de seguridad nacional aplicadas en los departamentos vecinos (Guaviare, Meta, Caquetá y Putumayo), específicamente del Plan Patriota y del Plan Colombia en su componente de erradicación forzada mediante aspersión aérea.

9- Las zonas de frontera colombianas del sur-oriente se están configurando como la manifestación de ineficacia de las políticas de seguridad. En estos territorios no se han mejorado los niveles de protección de la vida e integridad personal de sus habitantes en ellos, la presencia de la fuerza pública en décadas anteriores no ha sido permanente ni significativa y, por ende, han sido vulnerables a los mecanismos de regulación social, económica y territorial impuestos por los grupos armados irregulares; estas zonas han sido susceptibles de vincularse a redes del narcotráfico y otras formas del crimen organizado ante la ausencia de proyectos de desarrollo regional. Allí el poder formal es superado por el poder real de los violentos.

10- Tradicionalmente en América del Sur las fronteras han sido concebidas como espacios de seguridad por parte de los Estados. En la región andina la prioridad desde hace muchos años es fortalecer la presencia militar para prevenir o contener la expansión del conflicto armado colombiano hacia los países vecinos y para tratar de lograr el control territorial por parte de Colombia. Esta concepción ha dejado de lado, en la política pública de los Estados, el carácter urgente de la ayuda humanitaria en regiones fronterizas y las necesidades de protección de la población civil que huye de la confrontación armada hacia los países vecinos. ¿Cuando entenderemos que las fronteras deben unir y no separar a los pueblos hermanos?

\section{BIBLIOGRAFÍA}

ACTA DE CONTADORA. Documentos ACNUR.http://www.acnur.org/biblioteca/pdf/1566. Consultado el 16-sep-2007

BANCO INTERAMERICANO DE DESARROLLO

http//www.iadb.//ppp/pppambiental.asp. Consultado el 4-mar-2005

BRITO, Jorge. Intención del Plan Colombia es económica porque busca acelerar apertura de los mercados. En: el otro eje del mal. APDH. Quito. Ecuador. ISBN. 9978-22-296-0 2003

CADENA MONTENEGRO, José Luis. La Geografía y el Poder. Territorializacion del poder en Colombia. El caso FARC, de Marquetalia al Caguán. Tesis para obtener El título de Magíster en Geografía. UPTCIGAC. BOGOTÁ. 2002 
CADENA MONTENEGRO, José Luis. El Plan Puebla Panamá: una revisión geopolítica. Tesis para obtener en título de Doctor en Geografía. Universidad Nacional Autónoma de México. México, D.F. Junio de 2005

CADENA MONTENEGRO, José Luis. Los problemas fronterizos de Colombia. DIARIO EL COMERCIO, Quito. Entrevista de prensa. 20 de septiembre de 1999

FAO/CONAZA/SEDESOL. Plan de Acción para combatir la desertificación en México. Saltillo. México.1.994.

FERNÁNDEZ CHRISTLIEB, Paulina. El EZLN y la guerra de baja intensidad. Diario La Jornada de México. $24 / 03 / 2001$

GASCA ZAMORA. Espacios Transnacionales. Interacción, integración y fragmentación en la frontera México- Estados Unidos. Universidad Nacional Autónoma de México. Instituto de Investigaciones Económicas. ISBN 970-701-267-6. 2002

GUHL, Ernesto. Escritos geográficos: las fronteras políticas y los límites naturales. Bogotá. Fondo FEN Colombia. 1991

HERNÁNDEZ LÓPEZ Rafael. Los problemas fronterizos de Colombia. DIARIO EL COMERCIO, Quito. Entrevista de prensa. 20 de septiembre de 1999

GARCÍA RUIZ, Ramón. El Canal de Panamá. Biblioteca Enciclopédica Popular. Secretaría de Educación pública. México. 1945. Págs. 31 y 32

DEPARTAMENTO de Estado de los Estados Unidos de Norteamérica. Fact Sheet Bureau of Western Hemisphere Affaire Washington, D.C. May 16, 2001

KOHMAE, Kenichi. El próximo escenario global. Desafíos y oportunidades en un mundo sin fronteras. Grupo editorial Norma. México. 2005

LÓPEZ TRIGAL, Lorenzo y DEL POZO, Paz Benito. Geografía Política. Ediciones Cátedra S.A. Madrid. 1999

PÉREZ ESQUIVEL. Adolfo. El ALCA, además de una imposición económica, busca militarizar el continente. En: el otro eje del mal. APDH. Quito. Ecuador. ISBN. 9978-22-296-0. 2003 
SALAZAR PÉREZ, Robinson. Los avatares del Plan Colombia, Plan Dignidad y Plan Puebla Panamá. En: Revista Reflexión Política. Año 4 Nº 8. ISNN: 0124-0781. UNAB. Colombia/Convergencia. 2002.

TIRADO MEjÍA, Álvaro, Los tratados Torrijos-Carter y el Tratado de Montería. Derechos de Colombia, panamá y Estados Unidos en el Canal de Panamá. El Tiempo. Historia-Credencial-sucesos. 16-sep-2004

TRATADO URRUTIA-THOMSON. Enciclopedia Wikipedia.

http://es.wikipedia.org/wiki/Tratado_Thomson-Urrutia. Consultado el 20-sep-2007

TUIRÁN Rodolfo y ÁVILA José Luis. Delimitación de la franja fronteriza del norte de México. En: Situación demográfica de México 2002. Documento electrónico en Internet. www.conapo.gob.mx/ publicaciones/2002/07. Consultada en línea el 24 de enero de 2005 